NOTICE: this is the author's version of a work that was accepted for publication in Appetite. Changes resulting from the publishing process, such as peer review, editing, corrections, structural formatting, and other quality control mechanisms may not be reflected in this document. Changes may have been made to this work since it was submitted for publication. A definitive version was subsequently published in Appetite, Vol.75, (2014). DOI: 10.1016/j.appet.2014.01.006 
A QUALITATIVE EXPLORATION

1

2

3

4

5

6

7

9

10

11

12

13

14

15

16

17

18

19

20

21

22

23

24

25

A Qualitative Exploration of Experiences of Overweight Young and Older Adults: An Application of the Integrated Behaviour Model

Annaleise Robertson ${ }^{1}$, Barbara Mullan ${ }^{1,2^{*}}$, Jemma Todd $^{1}$

$\left(\frac{100}{20}\right.$

\section{Annaleise Robertson:}

${ }^{1}$ School of Psychology, University of Sydney, Sydney, NSW, 2006, Australia, Email:

annaleise.robertson@health.nsw.gov.au

\section{Barbara Mullan}

* corresponding author:

${ }^{1}$ School of Psychology, University of Sydney, Sydney, NSW, Australia, 2006, Email:

barbara.mullan@sydney.edu.au, Phone: +61 29351 6811, Fax: +61 290365223

${ }^{2}$ School of Psychology and Speech Pathology, Curtin University, Perth, WA, Australia, 6845,

7 Email: Barbara.mullan@curtin.edu.au, Phone: +61 89266 3473, Fax: +61 892662464

\section{Jemma Todd:}

${ }^{1}$ School of Psychology, University of Sydney, Sydney, NSW, 2006, Australia, Email:

jtod4038@uni.sydney.edu.au 


\section{Abstract}

While rates of obesity continue to increase, weight-loss interventions to date have not been hugely successful. The purpose of this study was to explore the specific factors that are relevant to weight control in overweight and obese young adults compared to older adults, within the context of the theory of planned behaviour (TPB). A qualitative methodology with purposive sampling was used. Semi-structured interviews were conducted with 23 young adults and older adults who were currently overweight or obese. The research was informed by thematic analysis. A mixed deductive-inductive approach that was structured around but not limited to TPB constructs was applied. Themes mapped onto the TPB behaviour well, with additional themes of motivation, and knowledge and experience emerging. Differences across groups included motivators to weight loss (e.g. appearance and confidence for young adults, health for older adults), importance of social influences, and perceptions of control (e.g. availability and cost for young adults, age and energy for older adults). Similarities across groups included attitudes towards being overweight and losing weight, and the value of preparation and establishment of a healthy routine. Finally, across both groups, knowledge and confidence in ability to lose weight appeared adequate, despite failed attempts to do so. The different experiences identified for younger and older adults can be used to inform future tailored weight-loss interventions that are relevant to these age groups, and the TPB could provide a useful framework. Additional intervention strategies, such as improving behavioural routine and improving self-regulation also warrant further investigation.

Keywords: qualitative; overweight; theory of planned behaviour; young adults; older adults 
A Qualitative Exploration of Experiences of Overweight Young and Older Adults: An

The worldwide prevalence of obesity is increasing (Cameron et al., 2003; Prentice, 2006). Australia is reported to have one of the highest prevalence rates of obesity in the world, with an estimated 60\% of the population being overweight or obese (Cameron et al., 2003). Current weight-loss interventions often use a combination of behavioural modification, pharmacological interventions and, in the most extreme cases, surgical procedures (Bauchowitz et al., 2005; Douketis, Macie, Thabane, \& Williamson, 2005; Ebbeling, Leidig, Feldman, Lovesky, \& Ludwig, 2007; Lang \& Froelicher, 2006; McMillanPrice et al., 2006). However, most weight-loss interventions result in a maximum of 5 to $10 \%$ weight-loss of initial body weight, which is typically regained within five years (Magro et al., 2008). Whilst many interventions have targeted young adults, the heterogeneity of results and poor long term maintenance outcomes highlights the need to improve the efficacy of current weight-loss treatments (Marcus et al., 2006).

Health models can form a useful theoretical basis to investigate the various factors that are important to target in weight-loss interventions. Further, interventions that are based on theoretical frameworks have been shown to be more effective than those that do not (Avery, Flynn, van Wersch, Sniehotta, \& Trenell, 2012). The theory of planned behaviour (TPB) is a well-researched model of health behaviour (e.g. McEachan, Conner, Taylor, \& Lawton, 2011), in which intention is posited as the most important behavioural determinant (Fishbein et al., 1992). The TPB also incorporates attitudes (behavioural evaluation) and subjective norms (social pressure), as well as perceived behavioural control over performance (Ajzen, 2002b; Fishbein, 2007). Perceived behavioural control not only serves as a predictor 
A QUALITATIVE EXPLORATION

of intention, but also serves to directly predict behaviour, as it is considered a proxy for actual control. The model has also been expanded to include self-efficacy as a form of behavioural control, which is considered the perceived ease with which the behaviour is performed (Ajzen, 2002b; Bandura, 1977).

The TPB proponents acknowledge that to understand the beliefs relating to the attitudes, subjective norm, perceived control and self-efficacy of a particular population, it is imperative to identify the beliefs specifically within that population (Ajzen, 2002a).

Therefore, an essential step in the application of this model is to elicit information about the behavioural, normative and control beliefs most relevant to the population being studied. Once this has occurred, appropriate measures and interventions can then be designed and tested.

There is a dearth of research using health behaviour models and qualitative research techniques to explore the factors relevant to weight-loss, and most of these studies have used a normal weight female sample, which may limit the generalisability to overweight or obese individuals (Andajani-Sutjahjo, Ball, Warren, Inglis, \& Crawford, 2004; Greaney et al., 2009; Nelson, Kocos, Lytle, \& Perry, 2009), and to males (Cluskey \& Grobe, 2009). Furthermore, research has tended to only explore one element of weight-loss related behaviour, such as healthy eating (Garcia, Sykes, Matthews, Martin, \& Leipert, 2010) or exercise (Allender, Cowburn, \& Foster, 2006; Belanger-Gravel, Godin, Bilodeau, Poirier, \& Dagenais, 2013; Downs \& Hausenblas, 2005). Therefore as a way of addressing these issues, a qualitative exploration of the TPB to explore factors relevant to weight-loss appears timely. The purpose of this research therefore was to qualitatively investigate the specific factors relevant to weight control and management in overweight and obese individuals, within a theoretical framework of the TPB, and to compare these factors across younger and older adults. A secondary aim of the research was to determine whether the TPB framework 
A QUALITATIVE EXPLORATION

100

101

102

103

104

105

106

107

108

109

110

111

112

114

115

116

117

118

119

120

121

122

123

124

provided an appropriate fit to overweight and obese individuals, and to weight management behaviours, so as to inform specific tailored and theoretically driven weight-loss interventions.

\section{Method}

\section{Overview and Design}

A qualitative research approach was used, combining in-depth semi-structured focus groups and individual interviews. Sampling used in this study included both purposive sampling and theoretical sampling (Braun \& Clarke, 2006). Data extraction was informed by thematic analysis techniques (Willig, 2001). Participants also completed a brief demographic and weight-loss information questionnaire. Participants were required to be aged 18 or over, be fluent in English, and have a BMI of 25 or over. An approximately equal number of males and females were recruited.

\section{Participants}

A total of 23 overweight and obese adults participated in the study. This included 17 young adults (18-26 years; 9 females), and 6 older adults (36-65 years; 4 females). See Table 1 for demographic characteristics. A majority of participants reported that they had tried to lose weight or control their weight in the past, with an average of six weight-loss attempts for young adults and three for older adults. The average weight-loss goal was 8.5 kilograms for older adults and 13.3 kilograms for younger adults.

Focus groups and interview times were organised based on individual participant's schedules and availability. As most of the older participants had less flexible availability, it was not possible to organise focus groups with this age group. Thus while all of the older adults participated in individual interviews, all of the younger adults participated in small focus groups. The focus groups ranged in size from two to six people.

\section{Materials}


A QUALITATIVE EXPLORATION

\section{Demographic questionnaire}

Data on age, sex, ethnicity, level of education, employment status and annual income were collected. Participants also provided self-reported measures of their height and weight, from which BMI was calculated. Information was also gathered on participants' history of weight-loss or management, including number of previous weight-loss attempts.

\section{Semi-structured interview}

All interviews and focus groups were conducted with the assistance of an interview guide that reflected the research questions, which is important for strong qualitative research (Leedy \& Ormond, 2005). The main topics for the semi-structured interview included selfperception of weight (e.g., “Do you perceive yourself as being overweight?”), previous personal experience with weight-loss (e.g., "Have you ever tried to lose weight before?”), personal control over weight-loss (e.g., "How much control do you think you have over your ability to lose weight?”), and the motivators and challenges for weight-loss as experienced by the individual (e.g., "What are the main things which motivate you to lose weight?” and “Are there people in your life who you think may make it more difficult for you to lose weight? If so, in what ways?”). It also explored attitudes towards weight-loss (e.g., "What are the disadvantages of trying to lose weight?”) and the influence of other people on attitudes and weight-loss efforts (e.g., “What do people say about your weight?”). The interview questions were used flexibly throughout the study, and the participants own language styles were adopted and incorporated into further questions. Probe and follow-up questions were used to clarify responses and encouraged elaboration (Bowling, 2002). In addition, participants were encouraged to pose their own questions if they felt there were any important issues that were not raised. Specific questions were added throughout the interview process in response to developing themes. Key topics that were not mentioned spontaneously by interviewees but were central to the research aims were then specifically probed for by the interviewer. 
A QUALITATIVE EXPLORATION

\section{Procedure}

Participants were recruited voluntarily through a university-based online study participation website (in exchange for course credit), and through University staff and student bulletins. This study was approved by the University human research ethics committee. Interested participants contacted the researcher via phone or email, and an interview or focus-group time was scheduled. All focus groups or interviews were held in a meeting room at an Australian university. Upon arrival, participants were provided with an information statement and informed written consent was obtained. Interviews were audio recorded and ranged from just over half an hour to nearly 2 hours in length. Each participant was free to stop the interview or withdraw from the focus group at any time.

Following the interview, participants were required to fill out the demographic questionnaire. All participants were then debriefed, and offered a Weight Control Starter Pack, which included a weekly food diary, information pamphlets about healthy eating and exercise, healthy recipes, and a free gym trial pass.

\section{Coding and Analysis of Qualitative Data}

Each recorded interview was transcribed verbatim prior to coding and thematic analysis procedures. The first half of the recordings across both samples was transcribed by the researcher, in order for the researcher to become immersed in the data. The remaining recordings were transcribed by a hired transcription service.

After reading each individual transcript twice, inductive and deductive coding of raw data transcripts was conducted. The themes and constructs of the theoretical model shaped the reading of the interviews and therefore took a deductive focus; however, the subthemes that emerged within the constructs were not guided, and therefore allowed for differences between younger and older adults within these constructs. Other themes that emerged from 


\section{A QUALITATIVE EXPLORATION}

the data were also included inductively. This dual approach has been recommended to improve the quality of work, particularly for the exploration of theories (Joffe, 2012).

During this process, the identification and organisation of information into themes and subthemes was carried out using descriptive labels. Coding was carried out by the investigator and an independent, experienced qualitative coder, in order to reduce subjective biases. Discrepancies were discussed and resolved, to create a common theme list. There was, however, a high level of agreement in themes between coders, with the primary difference being the labels given to the themes. Constant organising and re-assignment, comparison and refining of coded data were carried out in a cyclical manner. This was done by comparing emerging master themes, subthemes and categories that were being coded in new transcripts with existing themes in a back and forth movement between raw data and the thematic summary table. This ensured that only new independent master themes were added to the overall summary theme list, and that emerging subthemes and categories were systematically integrated under these master themes.

\section{Data Saturation}

Qualitative data collection is generally said to end when no new theoretical insights emerge that would further develop a conceptual theme (Bowling, 2002; Strauss \& Corbin, 1990). In accordance with recommended procedures by which saturation of themes is systematically conducted and reported (Francis et al., 2009), a stopping criterion of three interview or focus groups was set, whereby data collection would cease when no new master themes emerged from the data after three consecutive interviews (Francis et al., 2010). This was reached at 17 young adults in six focus groups, and after conducting six individual interviews with older adults, at which point saturation was deemed to have occurred. There were no discernible differences between those who were overweight and those who were 
A QUALITATIVE EXPLORATION

obese regarding thematic content, and therefore the experiences of these individuals were explored together.

\section{Clustering of Themes}

Once master themes and subthemes were clustered and refined into the final themes, integration of themes was then carried out within and between each focus group and interview transcript. The themes identified from the younger and older adults were also compared, in order to identify any similarities or differences between the two age groups, both within and between themes. These differences were then interpreted and explained (Creswell, 1998).

\section{Results}

Broad themes of intention and motivation, attitudes, social influence, personal control, knowledge and experience, and behaviour emerged. Example quotes are provided for younger adults $(\mathrm{Y})$, older adults $(\mathrm{O})$, males $(\mathrm{M})$, and females $(\mathrm{F})$ to illustrate the themes.

\section{Intention}

Intentions appeared similar across age groups, and no subthemes were identified. Females in particular reported that they intended to lose weight, e.g. "I'm trying to lose weight and getting into the habit of exercise.” (Y1, F). In contrast, males in both age groups reported a desire to increase muscle tone and muscle composition, usually in combination with a decrease in body fat, e.g. "Yeah, losing weight, not muscle weight, but fat. I try to have a low carb and high protein diet to build the muscles.” (Y13, M). Only three individuals were not actively engaged in weight-loss behaviours at the time of the study, and all three individuals reported preparing or intending to begin this soon, e.g. "I'm doing absolutely nothing but I'm thinking about what changes I can make. Changes I can gradually introduce.” (O1, F). It is unclear what differentiated those who were actively engaging their 
A QUALITATIVE EXPLORATION

222

223

224

225

226

227

228

230

231

232

233

234

235

236

237

238

239

240

241

242

243

244

245

246

weight-loss intentions and those who intended to soon, but it is possible that other TPB factors played a role.

\section{Motivation}

Motivation occurred across subthemes including appearance and confidence, health, dating, the media, intrinsic motivation, and weight comments from others. Both groups recognised that having high levels of continuing motivation was very important for weightloss and control, but was also difficult to maintain. The most widely stated motivator for weight-loss across both groups was to improve one's appearance, to be able to wear certain clothes, and to feel happy and confident as a result, e.g. "Well I think if you feel good about your appearance, then you're going to also feel good because you have more confidence.

That's a big one too. Confidence.” (Y16, F). For the majority of young adults and some older adults, appearance and confidence were more salient motivators than health, e.g. “Body shape and appearance is higher than health, yeah, definitely, for me.” (Y12, M). In contrast, half of the older adults claimed health was their primary motivator for wanting to lose weight, e.g. "I do care if I'm healthy. That's what I care about.” (O5, M).

One motivator for weight-loss which was raised specifically by young adults was to feel more confident when approaching people they find attractive, and forming intimate relationships, e.g. "I would also feel more comfortable in trying to have a boyfriend. My weight definitely holds me back in that department too.” (Y10, F). Both age groups also acknowledged that motivation was most effective if it was self-driven, rather than due to external pressures, e.g. “Unless you've got that internal drive too, that voice inside your head telling you to keep going and that you can do it, no amount of external things helping you is going to get you results. Ultimately you need to be doing it for yourself, and I know that." $(\mathrm{O} 2, \mathrm{~F})$

\section{Attitudes}


Four subthemes were identified within attitudes: attitudes toward weight-loss,

attitudes toward being overweight, attitudes toward being thin, and cognitive errors. General attitudes expressed towards weight-loss behaviours were negative, e.g. "Isn't it strange how when you're losing the weight, you feel horrible but you keep going?” (Y11, F). Both young and older adults described weight-loss behaviour as being unpleasant and requiring deprivation of things that they enjoy as well as hard work and time commitment, e.g. "I think it's also about what I know I'm missing out on if I do exercise more. I mean, my friends and family are often going out of an evening, seeing films or going out to dinner or for drinks. I'd have to miss out on all of that if I was prioritising exercise a couple of nights a week, or even just eating really healthily would inhibit my ability to just do things like that. I don't want to miss out." (O6, F). There was also a perception amongst young adults that healthy foods were not as satisfying, or tasty e.g. "Yeah, it's just giving up the things that you like, like certain foods which just taste better than the healthy stuff." (Y15, F). However, both age groups acknowledged that healthy weight-loss behaviours could also result in positive feelings such as feeling happy, comfortable and healthier. In addition, most older adults described exercise as a method of reducing stress, e.g. "It's just this really easy way of shutting down for a while or zoning out; just really letting your mind calm down and stop worrying about work and all of the things you have to do or haven't done yet. It's great.” (O6, F).

For both age groups, general attitudes towards being overweight were also expressed, such as feeling unhappy with their current weight and appearance, frustration with not being able to purchase clothes they like, or wear clothes that had previously fit them, e.g. "I hate being overweight. I hate it. I've got a one year old daughter so I've been able to kind of justify it to an extent but I have a real issue with the size I'm at now, it's just too big for my comfort zone. It has a negative impact on my self-image and I just hate how I look. I hate it." (O4, F). Older adults were more likely to acknowledge the increased health risks and medical 
A QUALITATIVE EXPLORATION

problems associated with being overweight compared to the young adults, e.g. "It's quite distressing to know that if your BMI is above a certain number then it's not good, it's a risk factor for various diseases. And that's what worries me about my weight” (O6, F). In contrast young adults reported the negative social consequences such as restricted participation in or enjoyment of social activities, or not feeling confident enough to form intimate relationships, e.g. "I'm uncomfortable, and I know I don't look good. I don't like choosing out what I'm going to wear today. I don't know. It makes me want to cry.” (Y16, F).

Young and older adults expressed predominantly positive attitudes towards being thin or successful weight-loss. Most individuals acknowledged that losing weight would lead to positive emotions, less stress, feeling more comfortable and attractive, improved self-esteem and confidence, being able to wear nice clothes, and being treated more positively, e.g. "I'm definitely more confident [at the] lower end [of my weight], feel more sprightly and more attractive and that sort of stuff." $(\mathrm{O} 2, \mathrm{~F})$.

Finally, although more common amongst younger adults, many individuals in both age groups displayed unhelpful thinking styles which contributed to their negative attitudes about being overweight and weight-loss. These thinking styles included black and white or extreme thinking, e.g. "When I say to myself 'I'm going to go on a diet' I really go on a diet but when I'm not I'm never in the middle, I always go to the two extremes.” (Y11, F). Other unhelpful thinking styles included making unhelpful or unrealistic comparisons to others and using labels, e.g. "And my sister has always been really slim, so I always compared myself to her... so I've always been the fat one out of the two sisters, which has always been annoying, and like, yeah, upsetting.” (Y9, F); justifying weight gain in ways that reduced personal responsibility, e.g. "Then I use this as an excuse not to go, cos I think 'Well I would have gone but my friend couldn't. Maybe next week." (Y14, M), and catastrophising or exaggeration and overestimation of negative consequences, e.g. "I end feeling so terrible and 
A QUALITATIVE EXPLORATION

upset, I look in the mirror and I can't believe how horrible I look. And then I sit there and I look at this unrealistic number, this size, and I'm like "I shouldn't" and you sit there in a shopping centre, I can't cry. But it's so frustrating.” (Y16, F).

\section{Social Influence}

Four areas of social pressure emerged: the media, family, friends, and professionals. Individuals agreed that there was a general social pressure to lose weight and be thin, particularly from the media, e.g. "The media definitely. That's a big thing. From watching music videos, from watching movies, from picking up $M X^{1}$ or any magazine, you know?” (Y5, M). Some young adults reported that the media provided motivation to lose weight. In contrast, older adults described actively attempting to resist it through the way they engage with and respond to such pressure, e.g. "Part of me has bought into it the fact that I want to be skinny, look good, feel better about myself so I feel like it's a bit ambiguous, part of me knows intellectually yes the pressure is there, part of me feels that if you were an intelligent person if you have a strong will power and a good sense of yourself who cares what society says. You can resist it. You don't have to buy into it.” (O1, F).

Family was a social influence for many, but the effect seemed highly varied. While some found criticisms from their family about being overweight helpful and motivating, others found it discouraging and hurtful. For many young adults, their parents were responsible for purchasing and preparing their food. For some individuals, this acted as a facilitator to weight-loss, e.g. "I eat what my mum gives me. Usually my mum makes all of my dinners and gives me a packed lunch, so my diet is pretty much all that I need." (Y4, M). In contrast, many older adults reported that looking after children took up a considerable amount of time and prevented them from engaging in healthy weight-loss behaviours, e.g. "My work and my kids take up time, which technically means that I have less time to exercise because of

\footnotetext{
${ }^{1} \mathrm{MX}$ is a free Australian commuter magazine
} 
A QUALITATIVE EXPLORATION

321

322

324

325

326

327

them, but that's certainly not their fault... but every parent accepts that's just part of the deal I think, so I'm okay with that.” (O5, M).

Specific to young adults was the role of friends and peers, and similarly to family these comments could be both helpful, e.g. "I guess if it’s your friends then like it's helpful to know because if they don't tell you, then who will? Cos often by the time you realise you're out of shape it's a bit too late." (Y3, M); and unhelpful, e.g. "Girls can be the opposite because they can try to sabotage you... if you are losing weight they're like, oh, you know I have chocolate?” (Y9, F). Some young adults found it difficult to engage in weight-loss behaviours whilst socializing, e.g. "When I go to parties or I meet up with friends, I don't go with my diet, I just eat whatever.” (Y13, M), whilst others had a preference for peer sports over individual exercise. "I think that social sports are more effective, and you're more likely to go back and do it again.” (Y5, M) Negative social comparisons with peers were common, e.g. "Like when I'm with my water polo team, they're all buff and big and I'm the smallest one muscle wise, biggest one weight wise, so I feel like I'm nothing compared to them. You end up comparing yourself to these people that are all really fit.” (Y8, M).

Regarding professionals, very few people had doctors comment on their weight, and those that did were mostly young adults. These were mostly negative experiences, in which doctors were critical and negative, or dismissive of the individual's weight concerns, e.g. " $A$ Doctor weighed me, they told me I was overweight. They recommended I lose weight... She was critical. [It made me feel] not very good. When people say critical things it makes me want to eat more which is really strange." (Y10, F). However, several younger and older adults reported that being accountable to professional weight-loss support teams was very helpful, e.g. "I've done weight watchers a couple of times and that always works and then I get confident and think I don't need it and it works for a long period of time not being on it and then gradually it comes back up." (O2, F). 
A QUALITATIVE EXPLORATION

\section{Personal Control}

Whilst exploring the role of personal control, subthemes emerged across the areas of external and internal barriers and facilitators, perceived control, self-efficacy, and the intention-behaviour discrepancy. Most people reported that limited time and changes in their environment or living situations (e.g. work schedules, having a baby) which disrupt their routine were barriers to weight-loss behaviours. Young adults also reported the availability of unhealthy foods, e.g. "Yeah, my mum puts chocolate around, so I basically pick it up and eat it. If it's in front of me, if it's available, if I see it, I will eat it.” (Y7, M), and perceived high cost of health foods and exercise methods such as the gym were major barriers, e.g. "Budget. Like not everyone can afford a gym membership. I mean they're pretty absurd.” (Y6, F). In contrast, one barrier raised by all older adults was age, and that their bodies no longer responded as well to weight-loss efforts, e.g. 'I'm finding it the hardest I've ever felt it because as you get older you just don't have the energy to exercise that you used to have. So it's really quite difficult. Your body just responds differently than what it used to. Weight loss is always a hard thing I think, but certainly the older you get, the harder it is.” (O5, M). However, social support was found to be an external facilitator across both age groups, as described in the theme of social influence. In addition, young adults found having a stable living situation conducive to weight-loss behaviours, particularly if other people, such as their parents, took control of their food purchase and preparation.

Internal barriers to weight-loss which were identified by both young and older adults included giving into temptation or craving to eat unhealthy foods, and relying on others to make them engage in weight-loss behaviours as opposed to taking responsibility for it themselves. Older adults reported that being disorganised and unprepared was an internal barrier, e.g. "You really need to be organised and have the healthy foods available, and the time to prepare it, and with everything else happening at the same time, I sometimes find it 
A QUALITATIVE EXPLORATION

difficult to prepare as much as I need to.” (O4, F), whilst younger adults reported getting into a healthy routine was a facilitator to weight-loss, e.g. "Yes, I'm getting lots of exercise after work. I've just made it part of my routine, so that kind of ensures that I do it. I've been writing down what I do each day." (Y17, M).

Many individuals felt that they have a high level of control over their ability to engage in weight-loss behaviours, and confidence in their ability to do so. However, this was in contrast to their actual experience, where they described extreme difficulty in engaging in and maintaining weight-loss behaviours, e.g., "I have the control to change things I just don't change them, and I don't know why. It's ridiculous.” (Y16, F). Similarly, regarding selfefficacy, a majority of individuals had high confidence in their ability to change, but displayed ongoing concerns about the difficulty of maintaining weight-loss and staying motivated. This contrast is also reflected in the discrepancies between intentions and behaviour across both younger and older adults, e.g. "But I'm there, I really, really, really want to be 65 kilos and I've got all the resources but it's not happening and I'm asking ‘Why?” (Y11, F).

\section{Knowledge and Experience}

Knowledge and experience subthemes emerged across healthy eating, exercise, health risks of being overweight, and experience of being overweight and of weight-loss. All participants interviewed indicated that they felt that they had a sufficient level of knowledge about what is required to live a healthy lifestyle and try to maintain or control their weight, including healthy eating and exercise, e.g. "I know the big factors are about healthy eating in the right proportions, engaging in enough exercise to keep your heart rate sustained for a certain amount of time, and reducing sedentary behaviour, which should really be happening if you're engaging in enough exercise anyway.” (O6, F). Both younger and older adults also demonstrated a sound knowledge about the risks of being overweight. 
A QUALITATIVE EXPLORATION

Regarding experience, both young adults and older adults reported that they had experienced minimal physical side effects or medical difficulties related to their weight, e.g. "I recently had a blood test as well. Everything was fine but yeah, I just feel my fat symptoms coming on and like I said, sweaty, I don't feel as agile I guess, and really unenergetic.” (Y11, F); with a majority of individuals purporting not to have experienced any. When asked about their previous experience with weight-loss or control, most people reported that they had attempted to lose weight previously, but had gained it back again, e.g. "Yeah, I'm the same, I couldn't put a number on it, it's just like since, yeah, probably around about the same time, it's just been on and off, and I've succeeded a few times but then I just tend to put it back on.” (Y15, F).

\section{Behaviour}

Behaviour subthemes that emerged included healthy or unhealthy eating, exercise and sedentary behaviour, realistic weight-loss goals; and unhealthy extreme behaviour. While individuals in both age groups tended to engage in some exercise, young adults typically reported engaging in higher amounts of exercise, e.g. "I do water polo ... I go to the gym extra on my own, and I play soccer sometimes. ” (Y8, M), whilst most of the older adults reported engaging in minimal or no exercise, e.g. “No, I don't exercise generally. I've been actually making an effort this week to exercise, just walking up to uni and back again to the station.” (O6, F). Both younger and older adults reported having a relatively high sedentary lifestyle.

All individuals reported having varying degrees of an unhealthy diet. Shared difficulties for both younger and older adults were overeating, and eating unhealthy foods. Another form of unhealthy eating shown by both groups, but particularly young adults was having big gaps between meals, and eating large, late meals as a result, e.g. "There's that 
A QUALITATIVE EXPLORATION

gigantic gap where I'm just "I'm hungry, I'm hungry" and then when it's time to eat again I just stuff myself and then it's dinner time already, because I eat so late.” (Y16, F).

Young adults also reported a greater range of unhealthy and extreme eating behaviours, including using food as a reward, eating in response to negative affect and eating in secret, e.g. "I've just been eating so much junk food, it's just really bad. I find that I'm really stressed and lately I've just been really stressed, so I eat. I've just been pigging out, like Maccas (McDonalds) for brekkie, I even sneakily eat it.” (Y11, F). Young adults also described extreme weight control behaviours, such as self-imposing severe dietary restrictions which would often lead to binge-eating, or exercising excessively, e.g. "I sometimes go through periods where I try to eat really healthily but actually restrict what I'm eating quite a lot, so I may get up and eat a small bowl of really healthy cereal for breakfast and then half a sandwich for lunch, but when I get home at dinner time I'm starving and tend to eat lots then. Too much.” (Y2, F). In contrast, older adults generally demonstrated a healthy, realistic approach to weight-loss, e.g. "I'm being realistic about it and I'm doing what I need to do. I don't want to be the next Brad Pitt, I just want to be considered healthy." $(\mathrm{O} 5, \mathrm{M})$.

\section{Discussion}

The primary aim of this study was to investigate the specific factors relevant to weight control in overweight and obese younger and older adults, within a TPB framework. From the TPB, attitudes, social norms, and perceived behavioural control are all proposed to influence intention, which subsequently influences behaviour. These constructs were all supported within the current themes, which is in accordance with previous qualitative research exploring beliefs about physical activity in overweight and obese older adults (BelangerGravel et al., 2013). Other quantitative research has also emphasised the importance of constructs such as intention in weight control behaviours for overweight and obese 
A QUALITATIVE EXPLORATION

individuals (Baranowski, Cullen, Nicklas, Thompson, \& Baranowski, 2003; Gardner \& Hausenblas, 2004).

While intention was an important theme amongst both older and younger participants, gender differences were evident in the younger age group. Young females spoke about wanting to lose weight and reduce body fat, while males described intentions to build muscle mass and 'bulk up.' This gender difference has been supported in the literature (Antin \& Paschall, 2011) and may be important in designing interventions in this age group. Motivation also emerged as a theme. Whilst it is not an explicit TPB construct, motivational factors that influence behaviour are captured within the construct of intention (Ajzen, 1991), and therefore does not appear to be in conflict with the TPB. Health was less of a motivator for younger participants than for older participants. Nonetheless both groups were more likely to endorse non-health related motivators for weight-loss and control, such as improved appearance and ability to wear certain clothes. Young adults also reported increased confidence, particularly in forming intimate relationships, as a motivator. These findings expand on previous research that found appearance was a motivator amongst young adults, while older adults prioritised health (Flynn Corwyn \& Benda, 1999). This has important implications for weight-loss interventions and campaigns, most of which emphasise health benefits (Foreyt \& Goodrick, 1994), as these interventions may be less effective for young adults .

Attitudes towards weight-loss related behaviours such as exercise and healthy eating were mostly negative, as previously found (Andajani-Sutjahjo et al., 2004). Negative attitudes towards being overweight were also evident. Young adults were particularly concerned about the social implications of being overweight, whilst older adults were more concerned about the negative health consequences. In contrast, attitudes towards being thin were overwhelmingly positive in both populations. Thus, cultivating positive attitudes 
A QUALITATIVE EXPLORATION

470

471

472

473

474

475

476

477

478

479

480

481

482

483

484

485

486

487

488

489

490

491

492

493

494

towards goal-directed weight-loss behaviours rather than focussing on the long term (and more difficult to achieve) target of being thin may be helpful for both age groups.

Social pressure to lose weight was felt by both younger and older participants, which confirms a strong bias against being overweight or obese, both within Australia and other western cultures (Puhl \& Brownell, 2001; Thomas, Hyde, Karunaratne, Herbert, \& Komesaroff, 2008). Younger adults expressed specific pressure from the media, whilst family was influential to both groups. Another important area of social influence was interactions with professionals. Although only a small number of young adults had been told that they were overweight or needed to lose weight by their GP, these experiences were generally negative and deterred them from seeking further help. Obesity discrimination within medical settings can lead to an avoidance of seeking healthcare (Puhl \& Brownell, 2001; Sansone, Sansone, \& Wiederman, 1998) and may therefore reduce professional support for weight-loss attempts. Therefore in addition to interventions targeting individuals, interventions aimed at reducing stigma towards overweight by health professionals are needed.

There were a number of external barriers to weight control raised by both groups, such as time limits and periods of change, which have been supported in the literature (Garcia et al., 2010; Nelson et al., 2009). Young adults also reported that the availability of unhealthy foods and cost of healthy foods were barriers to weight-loss behaviours, whilst older adults mentioned aging as a barrier. Internal barriers were also found; older adults reported being disorganised and unprepared as an internal barrier to weight control, whilst younger adults reported having a regular, organised routine facilitated healthy behaviours. Therefore, learning to become more organised and prepared in the context of a time limited schedule may be helpful, and may also increase perception of external control over weight-loss.

Knowledge and experience was an important theme in the current research that was not suggested by the TPB. Previous research has suggested that knowledge and accurate 
A QUALITATIVE EXPLORATION

495

496

497

498

499

500

501

502

503

504

505

506

507

508

509

510

511

512

513

514

515

516

517

518

519

weight perceptions may be important for weight control in overweight and obese individuals (Duncan et al., 2011; Shimokawa, 2013). Knowledge may be necessary in order to make informed behaviour changes, and further research could consider assessing knowledge adequacy prior to conducting weight management interventions. Most participants reported sufficient knowledge of weight-loss behaviours, but not necessarily the skills to perform these behaviours. This contrast between knowledge and skills may contribute to an unsuccessful history of repeated weight-loss attempts, and is in accordance with literature that suggests that while knowledge is needed to change behaviour it is not sufficient (Kenkel, 1991; Kothe \& Mullan, 2011).

Most participants reported engaging in unhealthy behaviours, such as overeating unhealthy foods, skipping meals and eating late, and leading highly sedentary lifestyles but found that their behaviour was most supportive of their weight-loss goals when they were able to establish routines, suggesting the need to incorporate strategies that help develop healthy habits (King, Mainous III, Carnemolla, \& Everett, 2009), such as self-monitoring (Todd \& Mullan, In Press), in interventions. Young adults also reported a greater range of extreme weight-loss behaviours, such as excessive dietary restrictions or levels of exercise. These unhealthy approaches have been found to be risk factors for further weight gain (Cooley \& Toray, 2001; Neumark-Sztainer et al., 2006). Therefore, young adults may benefit from interventions that focus on self-control and self-regulation, which have been found to be important for many health behaviours (Collins \& Mullan, 2011; Hagger, Wood, Stiff, \& Chatzisarantis, 2010).

\section{Limitations}

In this study, all younger adults participated in focus groups with at least one other person, and all older adults engaged in individual interviews, which may have differentially affected the degree to which participants felt comfortable and able to respond honestly, or the 
A QUALITATIVE EXPLORATION

520

521

522

523

524

525

526

527

528

529

530

531

532

533

534

535

536

537

538

539

540

541

542

543

degree to which they were engaged with the interview process. In addition, all participants were university students or staff members, which may limit transferability of the results to other populations. However, it may also serve as strength, as this group is at high risk of weight gain (Garcia et al., 2010). In this study, individuals who signed up for the study were willing to discuss their weight difficulties, potentially excluding those who are unlikely to seek professional or personal support in weight-loss. This study may also not have appealed to individuals who are unaware that they are overweight, which may be important for future studies in this area. Finally, the interviews were conducted within a deductive theory-driven framework, which serves as a limitation and a strength. Whilst other themes and factors outside the TPB may have been missed, there was room for other themes to emerge. In addition, this allowed for a more detailed exploration of the TPB. Furthermore, within the theory-driven themes, the interviews were inductive in nature, which allowed for important subthemes to emerge that were not guided.

\section{Strengths and Implications}

The current study used qualitative research to identify similarities and differences in the experiences of older and younger adults regarding being overweight and weight-loss behaviours. A theoretical basis was used to form the research and interview questions, which has been shown to increase the validity of qualitative research (Peters, 2010). Many themes were identified that are relevant to younger and older adults in their attempts to lose weight, which each have important implications for future intervention design. Targeting specific sub-themes, for example young adults appear more motivated to lose weight for appearance concerns, whilst older adults appear to be more concerned about health, may help to improve the relevance of weight-loss interventions. Finally, although not explored in the current research, differences in the experiences and change mechanisms between those who are 


\section{A QUALITATIVE EXPLORATION}

544 overweight and those who are obese warrant investigation, to provide further tailored

545 interventions.

\section{Conclusion}

Overweight and obese young adults in Australia appear to experience a range of

548 factors relevant to weight-loss and control. This study delineated pertinent themes that arise

549 in the experience of overweight and obese young adults in comparison to older adults, in

550 addition to testing the applicability of these themes to the TPB. The TPB was a useful

551 theoretical framework for exploring weight control in overweight and obese individuals; and

552 the importance of knowledge could be further explored. The clinical implications of this

553 research are particularly important given the increasing prevalence of obesity in young adults 554 and the limited efficacy of current treatments. 
A QUALITATIVE EXPLORATION

References

558

Ajzen, I. (1991). The theory of planned behavior. Organizational Behavior and Human Decision Processes, 50(2), 179-211. doi: 10.1016/0749-5978(91)90020-T

Ajzen, I. (2002a). Constructing a TPB questionnaire: Conceptual and methodological considerations. Retrieved October, 2013, from http://chuang.epage.au.edu.tw/ezfiles/168/1168/attach/20/pta_41176_7688352_57138 . pdf

Ajzen, I. (2002b). Perceived behavioral control, self-efficacy, locus of control, and the theory of planned behavior. Journal of applied social psychology, 32(4), 665-683. doi: 10.1111/j.1559-1816.2002.tb00236.x

Allender, S., Cowburn, G., \& Foster, C. (2006). Understanding participation in sport and physical activity among children and adults: A review of qualitative studies. Health Education Research, 21(6), 826-835. doi: 10.1093/her/cyl063

Andajani-Sutjahjo, S., Ball, K., Warren, N., Inglis, V., \& Crawford, D. (2004). Perceived personal, social and environmental barriers to weight maintenance among young women: A community survey. International Journal of Behavioral Nutrition and Physical Activity, 1(15), 1-7. doi: 10.1186/1479-5868-1-15

Antin, T. M., \& Paschall, M. J. (2011). Weight perception, weight change intentions, and alcohol use among young adults. Body image, 8(2), 149-156. doi: 10.1016/j.bodyim.2011.01.002

Avery, L., Flynn, D., van Wersch, A., Sniehotta, F. F., \& Trenell, M. I. (2012). Changing Physical Activity Behavior in Type 2 Diabetes: A systematic review and metaanalysis of behavioral interventions. Diabetes care, 35(12), 2681-2689. doi: 10.2337/dc11-2452 
A QUALITATIVE EXPLORATION

582

583

584

585

586

587

588

589

590

591

592

593

594

595

596

597

598

599

600

601

602

603

604

605

Bandura, A. (1977). Self-efficacy: Toward a unifying theory of behavioral change. Psychological Review, 84(2), 191-215. doi: 10.1037/0033-295X.84.2.191

Baranowski, T., Cullen, K. W., Nicklas, T., Thompson, D., \& Baranowski, J. (2003). Are current health behavioral change models helpful in guiding prevention of weight gain efforts? Obesity Research, 11(S10), 23S-43S. doi: 10.1038/oby.2003.222

Bauchowitz, A. U., Gonder-Frederick, L. A., Olbrisch, M.-E., Azarbad, L., Ryee, M.-Y., Woodson, M., .. . Schirmer, B. (2005). Psychosocial evaluation of bariatric surgery candidates: A survey of present practices. Psychosomatic Medicine, 67(5), 825-832. doi: 10.1097/01.psy.0000174173.32271.01

Belanger-Gravel, A., Godin, G., Bilodeau, A., Poirier, P., \& Dagenais, G. R. (2013). Physical activity beliefs among overweight/obese older adults: Results from a theory of planned behavior elicitation study. International Journal of Sport Psychology, 44(2), 145-159. Retrieved from: http://www.ijsp-online.com

Bowling, A. (2002). Research Methods in Health: Investigating Health and Health Services. Berkshire, UK: Open University Press.

Braun, V., \& Clarke, V. (2006). Using thematic analysis in psychology. Qualitative research in psychology, 3(2), 77-101. doi: 10.1191/1478088706qp063oa

Cameron, A. J., Welborn, T. A., Zimmet, P. Z., Dunstan, D. W., Owen, N., Salmon, J., . . . Shaw, J. E. (2003). Overweight and obesity in Australia: The 1999-2000 Australian diabetes, obesity and lifestyle study (AusDiab). Medical journal of Australia, 178(9), 427-432. Retrieved from: https://www.mja.com.au/

Cluskey, M., \& Grobe, D. (2009). College weight gain and behavior transitions: Male and female differences. Journal of the American Dietetic Association, 109(2), 325-329. doi: 10.1016/j.jada.2008.10.045 
A QUALITATIVE EXPLORATION

606 Collins, A., \& Mullan, B. (2011). An extension of the theory of panned behavior to predict

607

608

609

610

611

612

613

614

615

616

617

618

619

620

621

622

623

624

625

626

627

628

629

630 immediate hedonic behaviors and distal benefit behaviors. Food Quality and Preference, 22(7), 638-646. doi: 10.1016/j.foodqual.2011.03.011

Cooley, E., \& Toray, T. (2001). Disordered eating in college freshman women: A prospective study. Journal of American College Health, 49(5), 229-235. doi: 10.1080/07448480109596308

Creswell, J. W. (1998). Qualitative Inquiry and Research Design: Choosing Among Five Traditions. Oaks, CA: Sage Publications.

Douketis, J., Macie, C., Thabane, L., \& Williamson, D. (2005). Systematic review of longterm weight loss studies in obese adults: Clinical significance and applicability to clinical practice. International journal of obesity, 29(10), 1153-1167. doi: 10.1038/sj.ijo.0802982

Downs, D. S., \& Hausenblas, H. A. (2005). Elicitation studies and the theory of planned behavior: A systematic review of exercise beliefs. Psychology of Sport and Exercise, 6(1), 1-31. doi: 10.1016/j.psychsport.2003.08.001

Duncan, D. T., Wolin, K. Y., Scharoun-Lee, M., Ding, E. L., Warner, E. T., \& Bennett, G. G. (2011). Does perception equal reality? Weight misperception in relation to weightrelated attitudes and behaviors among overweight and obese US adults. International Journal of Behavioral Nutrition and Physical Activity, 8(1). doi: 10.1186/1479-5868$8-20$

Ebbeling, C. B., Leidig, M. M., Feldman, H. A., Lovesky, M. M., \& Ludwig, D. S. (2007). Effects of a low-glycemic load vs low-fat diet in obese young adults. Journal of the American Medical Association, 297(19), 2092-2102. doi: 10.1001/jama.297.19.2092

Fishbein, M. (2007). A reasoned action approach: Some issues, questions and clarifications. In I. Ajzen, D. Albarracin \& R. Hornik (Eds.), Prediction and Change of Health 
A QUALITATIVE EXPLORATION

631

632

633

634

635

636

637

638

639

640

641

642

643

644

645

646

647

648

649

650

651

652

653

654

Behavior: Applying the Reasoned Action Approach (pp. 281-295). Hillsdale, NJ: Erlbaum.

Fishbein, M., Bandura, A., Triandis, H. C., Kanfer, F. H., Becker, M. H., \& Middlestadt, S. E. (1992). Factors Influencing Behavior and Behavior Change: Final Report Theorist's Workshop. Rockville, MD: National Institute of Mental Health.

Flynn Corwyn, R., \& Benda, B. B. (1999). Examination of an integrated theoretical model of exercise behavior. American Journal of Health Behavior, 23(5), 381-392. doi: 10.5993/AJHB.23.5.7

Foreyt, J. P., \& Goodrick, G. K. (1994). Attributes of successful approaches to weight loss and control. Applied and Preventive Psychology, 3(4), 209-215. doi: 10.1016/S09621849(05)80095-2

Francis, J. J., Johnston, M., Robertson, C., Glidewell, L., Entwistle, V., Eccles, M. P., \& Grimshaw, J. M. (2010). What is an adequate sample size? Operationalising data saturation for theory-based interview studies. Psychology and Health, 25(10), 12291245. doi: 10.1080/08870440903194015

Garcia, A. C., Sykes, L., Matthews, J., Martin, N., \& Leipert, B. (2010). Perceived facilitators of and barriers to healthful eating among university students. Canadian Journal of Dietetic Practice and Research, 71(2), e28-e33. doi: 10.3148/71.2.2010.XX

Gardner, R. E., \& Hausenblas, H. A. (2004). Understanding exercise and diet motivation in overweight women enrolled in a weight-loss program: A prospective study using the theory of planned behavior. Journal of applied social psychology, 34(7), 1353-1370. doi: 10.1111/j.1559-1816.2004.tb02010.x

Greaney, M. L., Less, F. D., White, A. A., Dayton, S. F., Riebe, D., Blissmer, B., . . Greene, G. W. (2009). College students' barriers and enablers for healthful weight 
A QUALITATIVE EXPLORATION

655

656

657

658

659

660

661

662

663

664

665

666

667

668

669

670

671

672

673

674

675

676

677

678

679

management: A qualitative study. Journal of Nutrition Education and Behavior, 41(4), 281-286. doi: 10.1016/j.jneb.2008.04.354

Hagger, M. S., Wood, C., Stiff, C., \& Chatzisarantis, N. L. D. (2010). Ego depletion and the strength model of self-control: A meta-analysis. Psychological Bulletin, 136(4), 495525. doi: 10.1037/a0019486

Joffe, H. (2012). Thematic Analysis. In D. Harper \& A. Thompson (Eds.), Qualitative Research Methods in Mental Health and Psychotherapy: A Guide for Students and Practitioners (pp. 209-223). West Sussex, UK: John Wiley \& Sons.

Kenkel, D. S. (1991). Health Behavior, Health Knowledge, and Schooling. Journal of Political Economy, 99(2), 287-305. doi: 10.2307/2937682

King, D. E., Mainous III, A. G., Carnemolla, M., \& Everett, C. J. (2009). Adherence to healthy lifestyle habits in US adults, 1988-2006. The American journal of medicine, 122(6), 528-534. doi: 10.1016/j.amjmed.2008.11.013

Kothe, E. J., \& Mullan, B. A. (2011). Perceptions of fruit and vegetable dietary guidelines among Australian young adults. Nutrition \& Dietetics, 68(4), 262-266. doi: 10.1111/j.1747-0080.2011.01550.x

Lang, A., \& Froelicher, E. S. (2006). Management of overweight and obesity in adults: Behavioral intervention for long-term weight loss and maintenance. European Journal of Cardiovascular Nursing, 5(2), 102-114. doi: 10.1016/j.ejcnurse.2005.11.002

Leedy, P. D., \& Ormond, J. E. (2005). Practical Research: Planning and Design. New Jersey: Pearson Education.

Magro, D. O., Geloneze, B., Delfini, R., Pareja, B. C., Callejas, F., \& Pareja, J. C. (2008). Long-term weight regain after gastric bypass: A 5-year prospective study. Obesity surgery, 18(6), 648-651. doi: 10.1007/s11695-007-9265-1 
A QUALITATIVE EXPLORATION

680

681

682

683

684

685

686

687

688

689

690

691

692

693

694

695

696

697

698

699

700

701

702

703

704

Marcus, B. H., Williams, D. M., Dubbert, P. M., Sallis, J. F., King, A. C., Yancey, A. K., .. . Claytor, R. P. (2006). Physical activity intervention studies: What we know and what we need to know. Circulation, 114(24), 2739-2752. doi: 10.1161/ CIRCULATIONAHA.106.179683

McEachan, R. R. C., Conner, M., Taylor, N. J., \& Lawton, R. J. (2011). Prospective prediction of health-related behaviours with the theory of planned behaviour: A metaanalysis. Health Psychology Review, 5(2), 97-144. doi: $10.1080 / 17437199.2010 .521684$

McMillan-Price, J., Petocz, P., Atkinson, F., O'Neill, K., Samman, S., Steinbeck, K., .. . Brand-Miller, J. (2006). Comparison of 4 diets of varying glycemic load on weight loss and cardiovascular risk reduction in overweight and obese young adults: A randomized controlled trial. Archives of Internal Medicine, 166(14), 1466-1475. doi: 10.1001/archinte.166.14.1466

Nelson, M. C., Kocos, R., Lytle, L. A., \& Perry, C. L. (2009). Understanding the perceived determinants of weight-related behaviors in late adolescence: A qualitative analysis among college youth. Journal of Nutrition Education and Behavior, 41(4), 287-292. doi: 10.1016/j.jneb.2008.05.005

Neumark-Sztainer, D., Wall, M., Guo, J., Story, M., Haines, J., \& Eisenberg, M. (2006). Obesity, disordered eating, and eating disorders in a longitudinal study of adolescents: How do dieters fare 5 years later? Journal of the American Dietetic Association, 106(4), 559-568. doi: 10.1016/j.jada.2006.01.003

Peters, S. (2010). Qualitative research methods in mental health. Evidence-based mental health, 13(2), 35-40. doi: 10.1136/ebmh.13.2.35

Prentice, A. M. (2006). The emerging epidemic of obesity in developing countries. International Journal of epidemiology, 35(1), 93-99. doi: 10.1093/ije/dyi272 
A QUALITATIVE EXPLORATION

705

706

707

708

709

710

711

712

713

714

715

716

717

718

719

720

721

722

723

724

725

726

Puhl, R., \& Brownell, K. D. (2001). Bias, discrimination, and obesity. Obesity Research, 9(12), 788-805. doi: 10.1038/oby.2001.108

Sansone, R. A., Sansone, L. A., \& Wiederman, M. W. (1998). The relationship between obesity and medical utilization among women in a primary care setting. International Journal of Eating Disorders, 23(2), 161-167. doi: 10.1002/(SICI)1098108X(199803)23:2<161::AID-EAT6>3.0.CO;2-I

Shimokawa, S. (2013). When does dietary knowledge matter to obesity and overweight prevention? Food Policy, 38(0), 35-46. doi: 10.1016/j.foodpol.2012.09.001

Strauss, A., \& Corbin, J. (1990). Basics of Qualitative Research: Grounded Theory Procedures and Techniques. Newbury Park, CA: Sage Publications.

Thomas, S. L., Hyde, J., Karunaratne, A., Herbert, D., \& Komesaroff, P. A. (2008). Being 'fat'in today's world: A qualitative study of the lived experiences of people with obesity in Australia. Health expectations, 11(4), 321-330. doi: 10.1111/j.13697625.2008.00490.x

Todd, J., \& Mullan, B. (In Press). The role of self-monitoring and response inhibition in improving sleep behaviours. International Journal of Behavioral Medicine. doi: $10.1007 / s 12529-013-9328-8$

Willig, C. (2001). Introducing Qualitative Research in Psychology: Adventures in Theory and Method. Buckingham, UK: Open University Press. 
A QUALITATIVE EXPLORATION

727

728 Table 1

729 Summary of Participant Demographic Information

\begin{tabular}{lll}
\hline & Young Adults & Older Adults \\
\hline Number & 17 & 6 \\
Gender & 8 Female; 9 Male & 4 Female; 2 Male \\
Age range (mean; SD) & $18-26(19.9 ; 2.1)$ & $36-65(47.8 ; 11.8)$ \\
BMI range (mean; SD) & $25.8-43(29.1 ; 5.1)$ & $26.1-27.3(26.9 ; 0.5)$ \\
Weight loss attempts range (mean; SD) & $0-20(6.3 ; 5.7)$ & $0-10 \quad(3.2 ; 3.8)$ \\
Weight loss goal (kgs) range (mean; SD) & $0-30(13.3 ; 8.6)$ & $3-15(8.5 ; 4.2)$ \\
Ethnicity & & 4 \\
Anglo-Australian & 5 & 1 \\
Asian & 6 & 1 \\
\hline European & 6 &
\end{tabular}

730

731

732

733 